\title{
Atrial Fibrillation in the Intact Unanesthetized Dog: Hemodynamic Effects during Rest, Exercise, and Beta-Adrenergic Blockade*
}

\author{
Richard H. Martin, $\nmid$ Samuel T. Lim, $\ddagger$ and Robert L. Van Citters \\ (From the Department of Physiology and Biophysics, University of Washington, \\ Seattle, Wash.)
}

\begin{abstract}
Summary. The effects of atrial fibrillation were studied in 12 healthy unanesthetized dogs, 9 to 49 days after surgical implantation of transducers for measurement of aortic flow and left ventricular diameter. Atrial fibrillation and pacing at comparable ventricular rates were induced by electrical stimulation of the right atrial appendage, and their effects were compared with observations made during sinus rhythm in each dog. At rest, cardiac output and mean arterial pressure were not significantly different during sinus rhythm, atrial fibrillation, and atrial pacing. After beta-adrenergic blockade with propranolol, cardiac output during fibrillation was significantly less than that during pacing at comparable ventricular rates. Arterial pressure was not detectably altered. During moderately severe treadmill exercise by six dogs, cardiac output fell significantly upon induction of fibrillation. After pentobarbital anesthesia fibrillation caused decrements in cardiac output and arterial pressure that were accentuated after thoracotomy.

These observations suggest the existence of compensatory mechanisms that maintain an essentially constant cardiac output when atrial fibrillation is induced in healthy unanesthetized dogs at rest. These mechanisms appear to fail during moderately severe exercise, beta-adrenergic blockade, and pentobarbital anesthesia.
\end{abstract}

\section{Introduction}

The importance of atrial systole has been demonstrated in a variety of circumstances (1-8), but the hemodynamic significance of atrial fibrillation

* Submitted for publication August 1, 1966; accepted October 20, 1966.

Supported by a grant (HE-08433) from the National Institutes of Health and grants from the American Heart Association, the Washington State Heart Association, and the Northeastern Chapter of the Washington State Heart Association.

Presented in part at the National Meeting, American Federation for Clinical Research, Atlantic City, N. J., May 1, 1966.

† Address requests for reprints to Dr. Richard $H$. Martin, Dept. of Medicine, University of Missouri School of Medicine, Columbia, Mo.

$\$$ Present address : Dept. of Physiology, University of California San Francisco Medical Center, San Francisco, Calif. is less clearly established $(9,10)$. In patients with limited cardiac reserve the onset of atrial fibrillation is often attended by clinical deterioration, and the studies recently reviewed by McIntosh, Kong, and Morris (11) have generally shown an increase in cardiac output upon conversion of fibrillation to sinus rhythm in patients with heart disease. Data on the hemodynamic effects of atrial fibrillation in normal man are limited (12), but the onset of heart failure after the development of fibrillation in apparently healthy patients (13) has suggested a significant adverse effect of fibrillation even in the absence of detectable heart disease.

Experimental studies in animals have also demonstrated marked circulatory abnormalities during atrial fibrillation, with decrements in resting cardiac output of as much as $60 \%$. However, these experiments were conducted on open-chest prepa- 
rations (14-16) or no more than 24 hours after thoracotomy (17-19), and they were complicated by very rapid ventricular rates during atrial fibrillation in all but one series (16). In such circumstances cardiac performance is significantly altered (20-22). Thus, these results cannot be directly extrapolated to the healthy intact animal.

The present investigation was undertaken to assess some hemodynamic consequences of atrial fibrillation in the intact unanesthetized dog, both at rest and during exercise. The results show that fibrillation does not significantly alter cardiac output or mean arterial pressure at rest. They suggest the presence of a positive inotropic mechanism, previously postulated by several authors (14-16, 23), acting upon the heart during fibrillation.

\section{Methods}

During sodium pentobarbital anesthesia left thoracotomy was performed on 12 mongrel dogs weighing 17 to $25 \mathrm{~kg}$. Transducers were implanted for measurement of the blood flow in the ascending aorta (24) and the transverse diameter of the left ventricle (25). Bipolar stimulating electrodes set into an acrylic button were sutured to the right atrial appendage. Wires from the transducers and electrodes were brought through the posterior thoracic wall for subsequent connection to the appropriate electronic equipment. To preclude pericardial constriction, the pericardium was left widely open when the chest was closed. Experiments were not performed until the animal appeared to be in good health, 9 to 49 days after the operation. Each dog was alert, active, and eating well. Its heart rate and exercise tolerance had returned to preoperative levels.

Blood flow in the ascending aorta was determined with an ultrasonic flowmeter, which measures the difference in transit time of pulses of ultrasound transmitted alternately upstream and downstream, diagonally through the moving blood. The frequency response of this instrument is flat to 50 cycles per second, and its voltage output is a linear function of volume flow (24). Left ventricular diameter was measured with the sonocardiometer (25). Arterial pressure in the aortic arch was sampled through a catheter inserted during local anesthesia, via either a femoral or a carotid artery. Pressure was measured with a Statham P23 Db strain gauge or a miniature differential transformer pressure transducer (26).

Aortic flow velocity, left ventricular diameter, aortic pressure, and a continuous electrocardiographic tracing obtained from bipolar precordial electrodes were recorded and stored on magnetic tape by means of an eight-channel tape recorder. ${ }^{1}$ Stroke volume, cardiac

\footnotetext{
1 Model 3907A, Hewlett Packard, Sanborn Division, Waltham, Mass.
}

output, and heart rate were computed by analogue techniques (27). The voltage output of the aortic flowmeter was integrated over each cardiac cycle to obtain a galvanometer deflection that was proportional to stroke volume (minus systolic coronary flow per beat). Cardiac output (minus total coronary flow) was recorded by continuous integration of the aortic flowmeter output, with the integrator being reset to zero at the end of each 5-second interval. Since each dog served as its own control, only relative changes in cardiac output were considered significant. Consequently, volumetric calibration of the flow records was not performed. Heart rate was derived as the reciprocal of the time interval between aortic flow pulses, slightly damped by filtering through a resistance-capacitance ( $\mathrm{RC})$ network. The primary and derived variables were simultaneously recorded on a direct-writing oscillograph. ${ }^{2}$

Atrial arrhythmias. We induced atrial flutter or fibrillation by stimulating the right atrial appendage with 2 to $7-\mathrm{v}$ square wave pulses of $2 \mathrm{msec}$ duration at a rate of 50 pulses per second using pulse and wave form generators. $^{3}$ Atrial pacing was induced by similar pulses at the desired frequency. In two dogs the implanted electrodes were not effective, and atrial stimulation was accomplished by means of a bipolar electrode catheter placed, during local anesthesia, into the right atrium via a femoral vein. Although stimulus artifacts appeared on the electrocardiogram, atrial and ventricular depolarization potentials were still clearly distinguishable during atrial stimulation.

The criteria for fibrillation were these: $a$ ) an erratically irregular ventricular rhythm, plus $b$ ) either definite fibrillatory deflections of the base line of the electrocardiogram or flutter waves at rates exceeding 650 per minute with no regular interval between these waves and the QRS complexes. In most experiments both fibrillation and this very rapid flutter alternated during atrial stimulation. Two dogs developed only atrial flutter, which fulfilled the criteria listed above, and one dog had classical fibrillation during each episode of atrial stimulation. During atrial flutter, distinct flutter waves occasionally appeared on the tracings of the left ventricular diameter during diastole, indicating small but somewhat effective atrial contractions. However, constant intervals between atrial and ventricular systole did not occur, and no differences were detected in ventricular rate, stroke volume, or cardiac output during flutter and fibrillation in those animals which manifested both rhythms intermittently. Therefore, in the analysis of our results both rhythms have been treated together and are referred to as atrial fibrillation.

Resting studies. These experiments were performed with each dog lying quietly, generally on its right side. The animal's body position was kept constant, and every effort was made to keep it calm and relaxed. Records were obtained during sinus rhythm, atrial fibrillation, and

\footnotetext{
2 Model 958-2900A, Hewlett Packard, Sanborn Division, Waltham, Mass.

${ }^{3}$ Models 161 and 162, Tektronix, Inc., Beaverton, Ore.
} 
TABLE I

Ventricular rate and cardiac output in resting unanesthetized dogs*

\begin{tabular}{|c|c|c|c|c|c|c|c|c|}
\hline \multirow[b]{3}{*}{ I)og } & \multicolumn{4}{|c|}{ Control } & \multicolumn{4}{|c|}{ After propranolol } \\
\hline & \multicolumn{3}{|c|}{ Ventricular rate } & \multirow{2}{*}{$\begin{array}{c}\text { Relative } \\
\text { cardiac output } \\
\text { AF/AP }\end{array}$} & \multicolumn{3}{|c|}{ Ventricular rate } & \multirow{2}{*}{$\begin{array}{c}\text { Relative } \\
\text { cardiac output } \\
\text { AF/AP }\end{array}$} \\
\hline & $\overline{N S R}$ & $\mathrm{AF}$ & AP & & $\overline{\text { NSR }}$ & AF & $\overline{\mathbf{A P}}$ & \\
\hline & \multicolumn{3}{|c|}{ beats/min } & \multicolumn{5}{|c|}{ beats/min } \\
\hline A5 & 75 & 100 & 95 & 0.95 & & & & \\
\hline A10 & 102 & 138 & 141 & 1.00 & 96 & 134 & 127 & 0.81 \\
\hline S1 & 59 & 91 & 92 & 0.91 & 60 & 80 & 92 & 0.84 \\
\hline $\mathrm{S} 2$ & 104 & 124 & 115 & 0.94 & 102 & 101 & 105 & 0.86 \\
\hline S4 & 93 & 112 & 96 & 1.00 & 86 & 108 & 112 & 0.98 \\
\hline L1 & 115 & 136 & 132 & 0.99 & 98 & 122 & 126 & 0.86 \\
\hline A19 & 81 & 105 & 107 & 0.96 & 86 & 112 & 114 & 0.89 \\
\hline S5 & 165 & $310(-143) \dagger$ & 300 & 0.85 & 103 & 146 & 143 & 0.72 \\
\hline L3 & 76 & 156 & 120 & 1.00 & 68 & $191(-45)$ & 120 & 0.99 \\
\hline L4 & 90 & 129 & 130 & 1.02 & 105 & 142 & 132 & 0.97 \\
\hline L5 & 83 & 128 & 126 & 0.94 & 68 & 101 & 98 & 0.93 \\
\hline A25 & 62 & $\begin{array}{r}120 \\
76\end{array}$ & $\begin{array}{r}120 \\
66\end{array}$ & 1.00 & 90 & 135 & 140 & 0.98 \\
\hline Mean & 92 & 134 & 127 & 0.96 & 87 & 125 & 119 & 0.89 \\
\hline SD & \pm 27 & \pm 57 & \pm 56 & \pm 0.05 & \pm 15 & \pm 28 & \pm 16 & \pm 0.08 \\
\hline & & & & $>0.05$ & & & & $<0.01$ \\
\hline
\end{tabular}

* Abbreviations: NSR = sinus rhythm; $\mathrm{AF}=$ atrial fibrillation $; \mathrm{AP}=$ atrial pacing ; and $\mathrm{AF} / \mathrm{AP}=\mathrm{ratio}$ of output during fibrillation to that during atrial pacing.

$\dagger$ Values in parentheses indicate pulse deficits.

atrial pacing at a rate closely comparable to the average ventricular rate during atrial fibrillation. The order of these rhythms was randomized, and each was continued for 3 minutes or until a stable state had been achieved. Occasionally atrial fibrillation persisted up to $40 \mathrm{~min}$ utes after discontinuation of atrial stimulation.

After the completion of two or three sets of control observations, 11 of the 12 dogs were given propranolol 4 (1-isopropylamino-3-[1-naphthyl oxy]-2-propanol hydrochloride), $0.5 \mathrm{mg}$ per $\mathrm{kg}$ intravenously, over a period of 1 minute. The induction of beta-adrenergic blockade by this drug was established by demonstrating little or no cardiovascular response to isoproterenol (1 $\mu \mathrm{g}$ per $\mathrm{kg}$, intravenously) injected rapidly (28). After the measured variables had stabilized during beta-adrenergic blockade, two or three sets of observations were made during sinus rhythm, atrial fibrillation, and atrial pacing in the same manner as the control observations.

Exercise studies. Six dogs were trained to run on a motor-driven treadmill, with the speed and grade ( 3.0 to 6.3 miles per hour, 13.7 to $15.0 \%$ grade) adjusted to achieve the heaviest work load that each animal would tolerate for repeated runs. On a subsequent day observations were made while the dog stood quietly on the treadmill and during 5-minute periods of exercise at a constant work load. During each exercise period sinus rhythm was studied for 1 minute after the variables had stabilized. At this point atrial fibrillation was induced, and observations were repeated after stabilization had again occurred. Recovery periods of at least 15 minutes were allowed between duplicate exercise periods. In three dogs

4 Kindly furnished as Inderal by Dr. Alex SahagianEdwards, Ayerst Laboratories, New York, N. Y. rhythm was changed from sinus rhythm to atrial fibrillation to atrial tachycardia at various rates during a more prolonged exercise period.

Studies during anesthesia and thoracotomy. In two dogs comparisons of the three cardiac rhythms were repeated in sequence while the animal was resting, after he had been anesthetized with sodium pentobarbital (22 $\mathrm{mg}$ per $\mathrm{kg}$, intravenously), and after left thoracotomy with exposure of the heart during positive pressure respiration.

Statistical analysis. Data for analysis were selected from records of stable cardiac performance, generally 3 minutes after the onset of a new rhythm. The analogue computed records of cardiac output and pulse rate were used as indicators of stability during an experiment and for illustration of gross changes in these variables. For statistical analysis pulse rate was obtained more precisely by counting aortic flow pulses on 1-minute records sampled during stable periods. A more precise index of cardiac output was also obtained from these samples by measuring the stroke volume of each beat, averaging these values, and multiplying by the mean pulse rate. Significance was tested by analysis of variance or a $t$ test for paired data.

\section{Results}

Resting hemodynamics. The resting heart rates of 11 of the 12 dogs were below 120 beats per minute, and each showed marked sinus arrhythmia (Table I). During atrial fibrillation their electrocardiographically determined ventricular rates were below 160 . When the twelfth dog (S5) was 


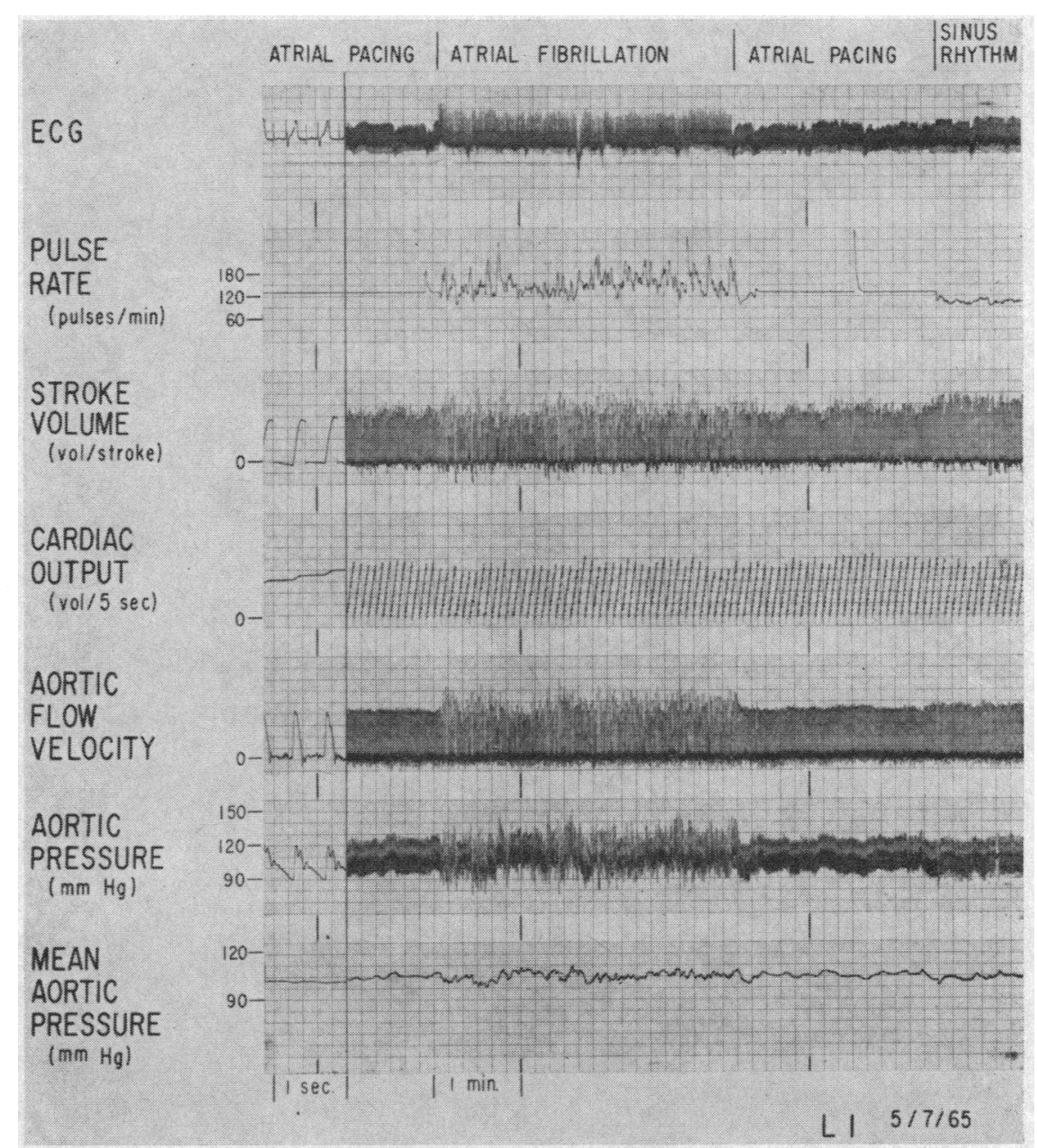

Fig. 1. Hemodynamic efFects of atrial pacing, atrial fibrillation, and SINUS RHYTHM. Phasic wave forms of parameters are shown at left. During atrial fibrillation marked beat-to-beat variations are present, but cardiac output and mean arterial pressure remain essentially constant and unchanged from values during sinus rhythm and atrial pacing. (Pulse rate record contains several spikes due to triggering of ratemeter by artifacts.) ECG = electrocardiogram.

in his cage before the experiment, his heart rate was 90 . Throughout the control period he was excited; his average ventricular rate was 165 beats per minute during sinus rhythm and 310 during atrial fibrillation. He was the only animal to manifest a pulse deficit (difference between rate of QRS complexes and aortic flow pulses) during control observations. The mean heart rate for all dogs during atrial pacing was slightly slower than the mean ventricular rate during atrial fibrillation, because several of them developed second-degree atrioventricular block during atrial pacing. The rate of pacing was always sufficiently slow to preclude significant block.
Mean cardiac output was $2.9 \% \pm 14.5 \% \mathrm{SD}$ greater during atrial pacing than during sinus rhythm; this difference is not statistically significant. In 11 dogs, cardiac output during atrial fibrillation ranged from $2 \%$ greater to $9 \%$ less than that during atrial pacing. Dog S5, which manifested a large pulse deficit, showed $15 \%$ less output during atrial fibrillation than during atrial pacing. Mean cardiac output during atrial fibrillation was $3.8 \% \pm 5.0 \%$ SD less than that during atrial pacing ( $\mathrm{p}>0.05)$.

Figure 1 is a typical record obtained during the three rhythms. It shows an essentially constant cardiac output with a slight fall in mean arterial 


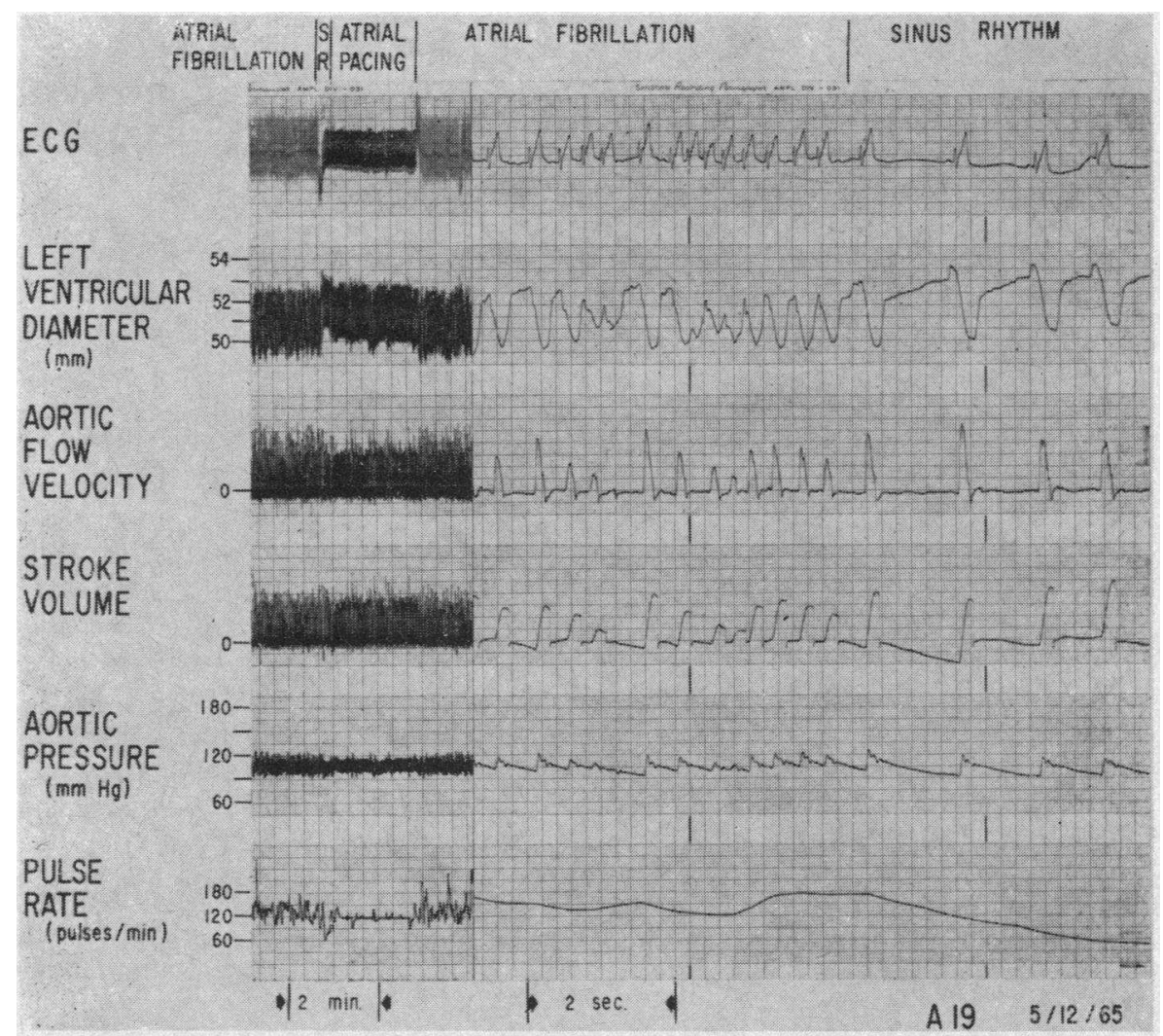

Fig. 2. Effects of atrial fibrillation, sinus RHYThM, AND ATRIAL PACING ON LEFT VENTRICULAR DIAMETER AND FUNCTION. Left: tracing at slow paper speed shows increase in end-diastolic and end-systolic diameter upon conversion to sinus rhythm (SR). Atrial pacing at a rate comparable to average ventricular rate during atrial fibrillation was begun 20 seconds later; 2 minutes later atrial fibrillation was reinstituted. Right: records at fast paper speed during persistent atrial fibrillation after atrial stimulation had been stopped. Note the prominent effect of atrial systole upon ventricular diameter after conversion to sinus rhythm.

pressure at the onset of fibrillation. In magnitude this decrease was comparable to the spontaneous fluctuations in pressure that occurred during atrial pacing, and a consistent reduction in arterial pressure at the onset of atrial fibrillation was not demonstrated in any dog. In those dogs in which atrial fibrillation persisted for prolonged periods neither cardiac output nor arterial pressure showed any consistent change with time.

Records of the diameter of the left ventricle were obtained in four dogs (Figure 2). End-diastolic and end-systolic diameters varied considerably from beat to beat during atrial fibrillation. When compared to measurements during sinus rhythm, the average end-diastolic diameter was always smaller during atrial fibrillation, which was accompanied by a faster ventricular rate. End-diastolic diameter was slightly larger during atrial pacing than during fibrillation at an identical average ventricular rate. The difference in each instance was comparable to the change in diameter induced by atrial systole. From records such as that shown in Figure 2 an index of stroke work was calculated by multiplying stroke volume and mean ejection pressure for each beat. Figure 3 shows a plot of end-diastolic diameter against stroke work for the last 31 beats of an episode of atrial fibrillation with an average ventricular rate of 126 beats per minute in dog L3. The values for these beats form a typical Starling curve. Immediately after conversion to sinus rhythm the ventricular rate slowed and beats 1 to 4 occurred. Just before beat 5 atrial pacing was instituted and clusters of values were obtained at ventricular rates of 124 and 168. A given level of stroke work was produced from a smaller end-diastolic diam- 


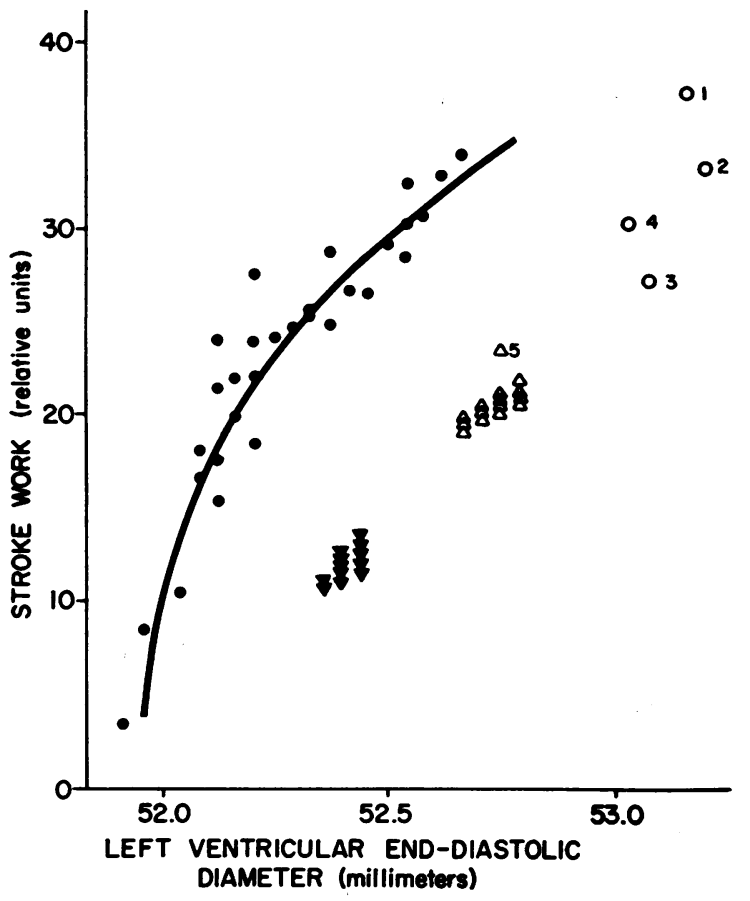

Fig. 3. LEFT ventricular STROKE WORK PLOTTED AGAINST LEFT VENTRICULAR END-DIASTOLIC DIAMETER. Solid dots: values for the last 31 beats during an episode of atrial fibrillation at an average ventricular rate of 126. Open circles: values for 4 consecutive beats immediately after spontaneous conversion to sinus rhythm. Triangles: values for beats during atrial pacing at rates of 124 (open) and 168 (solid).

eter during atrial fibrillation than during the rhythms with effective atrial contractions.

Beta-adrenergic blockade. After infusion of propranolol, heart rates tended to be slightly reduced (mean 87 beats per minute), especially in dog S5. Cardiac output was reduced by an aver- age of $8 \%$ during beta-adrenergic blockade in the 11 dogs studied before and after propranolol administration, but arterial pressure was unaltered. Essentially complete blockade of the cardiovascular effects of isoproterenol was induced in 9 of the 11 dogs; 2 dogs showed markedly attenuated, but still detectable, responses to the drug. After propranolol infusion, cardiac output was lower during atrial fibrillation than during atrial pacing in every dog. The average reduction in output, $11 \% \pm 8 \%$, is significant at the $1 \%$ level of confidence. In each dog atrial fibrillation caused a larger fall in output after propranolol; the difference in the effect of atrial fibrillation before and after propranolol is significant at the $2 \%$ level.

Exercise. Treadmill exercise increased cardiac output to levels two to three times the resting output during sinus rhythm (Table II). The average ventricular rate during sinus rhythm was $224 \pm 12$ beats per minute; during atrial fibrillation it was $315 \pm 26$ (Table II). No pulse deficit was present during fibrillation. Cardiac output was 4 to $16 \%$ lower during fibrillation than during sinus rhythm (mean, $10.4 \% \pm 4.6 \% \mathrm{SD}$, $\mathrm{p}<0.01$ ).

Atrial pacing at rapid rates during exercise was not studied systematically. In the three dogs studied in this manner cardiac output was not altered by atrial pacing at rates comparable to their ventricular rates during atrial fibrillation. A record from one of these dogs is shown in Figure 4. Exercise was begun during sinus rhythm with the heart rate gradually rising to a plateau at 240 beats per minute. At the point indicated by the first arrow the rate was abruptly increased to 300

TABLE II

Ventricular rate and cardiac output during exercise

\begin{tabular}{|c|c|c|c|c|c|c|}
\hline \multirow[b]{3}{*}{ Dog } & \multirow{2}{*}{\multicolumn{2}{|c|}{ Treadmill setting }} & \multirow{2}{*}{\multicolumn{2}{|c|}{ Ventricular rate }} & \multicolumn{2}{|c|}{ Relative cardiac output } \\
\hline & & & & & \multirow{2}{*}{$\frac{\text { NSR Ex. }}{\text { NSR Rest }}$} & \multirow{2}{*}{$\frac{\text { AF Ex. }}{\text { NSR Ex. }}$} \\
\hline & Speed & Grade & NSR & $\mathbf{A F}$ & & \\
\hline & $m p h$ & $\%$ & \multicolumn{2}{|c|}{ beats/min } & & \\
\hline $\begin{array}{l}\text { A10 } \\
\text { L1 } \\
\text { A19 } \\
\text { S5 } \\
\text { L4 } \\
\text { A25 }\end{array}$ & $\begin{array}{l}3.0 \\
3.5 \\
4.8 \\
6.3 \\
4.8 \\
4.8\end{array}$ & $\begin{array}{l}13.7 \\
13.7 \\
13.7 \\
13.7 \\
13.7 \\
15.0\end{array}$ & $\begin{array}{l}212 \\
208 \\
245 \\
228 \\
230 \\
221\end{array}$ & $\begin{array}{l}262 \\
330 \\
324 \\
330 \\
306 \\
340\end{array}$ & $\begin{array}{l}2.05 \\
3.12 \\
3.11 \\
2.18 \\
2.35 \\
2.41\end{array}$ & $\begin{array}{l}0.91 \\
0.96 \\
0.91 \\
0.84 \\
0.93 \\
0.84\end{array}$ \\
\hline $\begin{array}{l}\text { Mean } \\
\text { SD } \\
\text { p }\end{array}$ & & & $\begin{array}{r}224 \\
\pm 12\end{array}$ & $\begin{array}{r}315 \\
\pm 26\end{array}$ & $\begin{array}{r}2.49 \\
\pm 0.45\end{array}$ & $\begin{array}{r}0.90 \\
\pm 0.05 \\
<0.01\end{array}$ \\
\hline
\end{tabular}




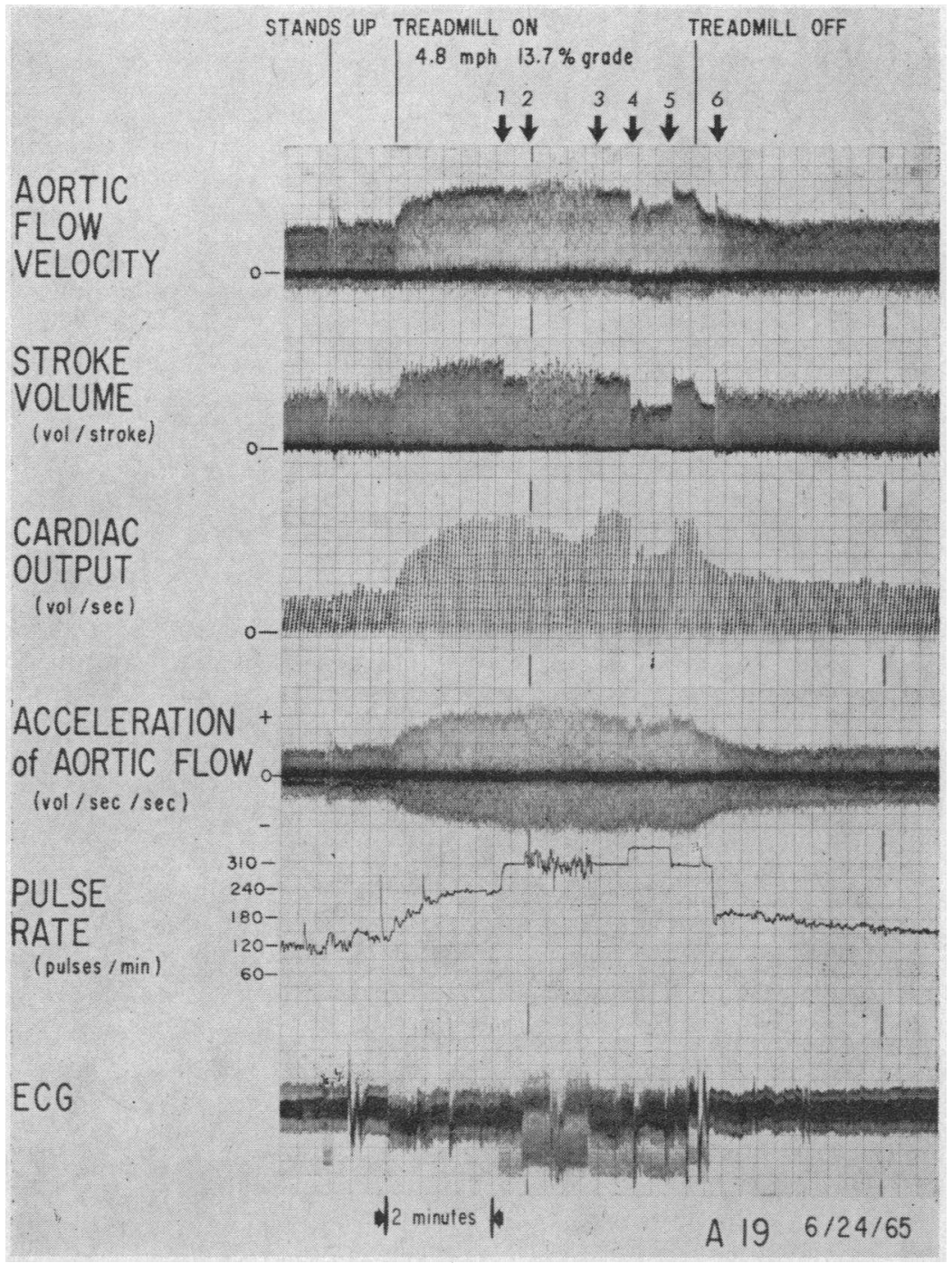

Fig. 4. EFFECTS OF SINUS RHYTHM, ATRIAL Fibrillation, AND ATRIAL PACING AT TWO RATES DURING EXERCISE. Details are in the text. The acceleration record was obtained by continuous differentiation of aortic flow velocity.

by atrial pacing, but cardiac output did not change. At the second arrow atrial fibrillation was induced, with an average ventricular rate of 300 , and cardiac output decreased abruptly. Atrial pacing at 300 beats per minute was reinstituted at the third arrow (with immediate conversion of atrial fibrillation), and cardiac output promptly rose to a level comparable to the control output. At the fourth arrow the rate of pacing was increased to 390 , and cardiac output fell to about $80 \%$ of its control value. However, when the rate was returned to 300 (arrow 5), cardiac output returned to its control level. Atrial fibrillation during exercise did not induce apparent distress in any dog.

Sodium pentobarbital and thoracotomy. Table III summarizes the cardiac performance in two dogs before and after pentobarbital anesthesia and after the left chest had been opened wide to expose the heart. The record for dog A25 during this experiment is shown in Figure 5. The heart rate, cardiac output, and arterial pressure before anesthesia conformed to the results obtained in the earlier series. After pentobarbital was administered the ventricular rate was faster during both 
TABLE III

Ventricular rate and cardiac output during atrial fibrillation in conscious, anesthetized, and open-chested dogs

\begin{tabular}{|c|c|c|c|c|c|c|c|c|c|}
\hline \multirow[b]{3}{*}{ Dog } & \multirow[b]{3}{*}{ Status } & \multirow{2}{*}{\multicolumn{2}{|c|}{ Sinus rhythm }} & \multirow{2}{*}{\multicolumn{2}{|c|}{ Atrial fibrillation }} & \multirow{2}{*}{\multicolumn{2}{|c|}{ Atrial pacing }} & \multicolumn{2}{|c|}{$\begin{array}{l}\text { Relative cardiac } \\
\text { output }\end{array}$} \\
\hline & & & & & & & & \multirow{2}{*}{$\overline{\frac{\mathrm{AF} \dagger}{\mathrm{NSR}}}$} & \multirow{2}{*}{$\frac{\mathrm{AF} \ddagger}{\mathrm{AP}}$} \\
\hline & & Rate & $\mathrm{CO}^{*}$ & Rate & $\mathrm{CO}$ & Rate & $\mathrm{CO}$ & & \\
\hline A19 & $\begin{array}{l}\text { Conscious } \\
\text { Pentobarbital } \\
\text { Thoracotomy }\end{array}$ & $\begin{array}{r}88 \\
173 \\
166\end{array}$ & $\begin{array}{r}1,000 \\
1,222 \\
854\end{array}$ & $\begin{array}{l}118 \\
260(-8) \S \\
258(-113)\end{array}$ & $\begin{array}{r}1,021 \\
1,059 \\
678\end{array}$ & $\begin{array}{l}108 \\
255 \\
256(-128)\end{array}$ & $\begin{array}{r}1,052 \\
1,142 \\
680\end{array}$ & $\begin{array}{l}1.02 \\
0.87 \\
0.79\end{array}$ & $\begin{array}{l}0.97 \\
0.93 \\
1.00\end{array}$ \\
\hline $\mathrm{A} 25$ & $\begin{array}{l}\text { Conscious } \\
\text { Pentobarbital } \\
\text { Thoracotomy }\end{array}$ & $\begin{array}{r}75 \\
146 \\
192\end{array}$ & $\begin{array}{r}1,000 \\
943 \\
606\end{array}$ & $\begin{array}{l}118 \\
255(-46) \\
277(-134)\end{array}$ & $\begin{array}{r}1,126 \\
769 \\
366\end{array}$ & $\begin{array}{l}122 \\
237 \\
290(-145)\end{array}$ & $\begin{array}{r}1,157 \\
961 \\
463\end{array}$ & $\begin{array}{l}1.12 \\
0.82 \\
0.60\end{array}$ & $\begin{array}{l}0.97 \\
0.80 \\
0.80\end{array}$ \\
\hline
\end{tabular}

* Cardiac output, expressed in relative units.

+ Ratio of values during atrial fibrillation and normal sinus rhythm.

$¥$ Ratio of values during atrial fibrillation and atrial pacing.

$\S$ Values in parentheses indicate deficit.

sinus rhythm and atrial fibrillation, and modest pulse deficits appeared during fibrillation. In both dogs cardiac output decreased during atrial fibrillation. Mean arterial pressure was slightly depressed during fibrillation, but comparable values were obtained during atrial pacing and sinus rhythm. After thoracotomy much larger pulse deficits appeared during fibrillation. In addition, rapid atrial pacing now induced marked pulsus alternans, with every other beat failing to open the aortic valve. In both dogs atrial pacing reduced cardiac output by approximately $20 \%$. In dog A19 there was no difference in output between atrial fibrillation and atrial pacing, but in dog A25 atrial fibrillation reduced output by an additional $20 \%$. Arterial pressure was clearly depressed at the onset of atrial fibrillation in both dogs and tended to return toward control levels while fibrillation persisted.

\section{Discussion}

Although the term "cardiac output" has been used to describe the computed volume of blood passing through the aorta, it is recognized that this value differed from the true cardiac output by the amount of blood entering the coronary system. The records of cardiac output obtained by continuous integration of aortic flow excluded both systolic and diastolic flow from the estimate; however, the technique used to estimate cardiac output for statistical analysis deleted only systolic coronary flow. If the coronary flow changed significantly during our experiments, our tacit assumption that changes in cardiac output were closely approximated by the changes in aortic flow would be in error. Unfortunately, the only reports on coronary flow during atrial fibrillation $(15,29)$ involved conditions which so reduced cardiac output and arterial pressure that no inferences can be made regarding the occurrence or magnitude of such an error in our data. Although absolute values were not obtained, in other respects the method used to estimate relative cardiac output appears to compare favorably with the indicator dilution and direct Fick techniques. Samples of stroke volume and heart rate were averaged for periods that exceeded the time generally required for inscription of dye curves or sampling of blood. In addition, the continuous record of aortic flow permitted calculations to be made only when the cardiac output had reached a stable state.

Spontaneous changes in heart rate, cardiac output, and arterial pressure may exceed those induced by our experimental manipulations. Although spontaneous changes were minimized by controlling the animal's posture and attempting to prevent extraneous stimuli, steady values seldom persisted for more than several minutes. To minimize such variation, the most critical comparisons - between atrial fibrillation and atrial pacingwere performed in close temporal sequence. In contrast, the periods of sinus rhythm and atrial fibrillation selected for analysis were frequently separated by an interval of atrial pacing, and the comparison of these rhythms yielded a larger standard deviation, $14.5 \%$ compared to $5.0 \%$.

Atrial fibrillation, when compared to sinus rhythm, induced a moderate increase in ventricular 


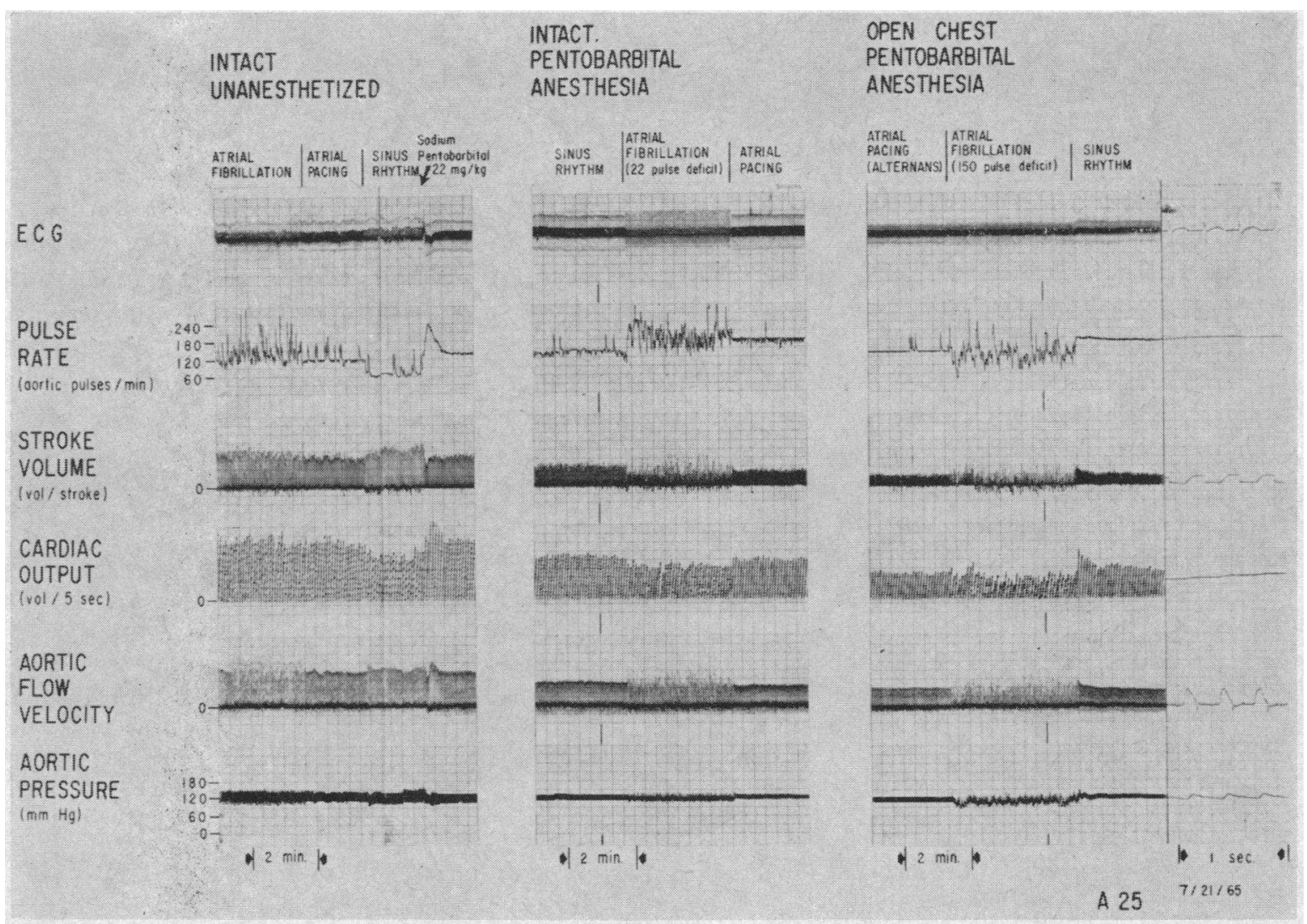

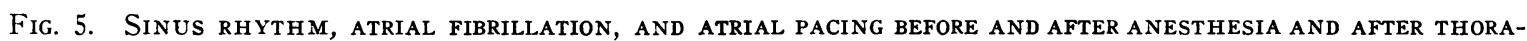
сотому. The ratemeter responded to aortic flow pulses; therefore, the rate record represents ventricular rate minus pulse deficit during fibrillation and one-half of the ventricular rate during atrial pacing after thoracotomy when pulsus alternans was present. Pulse deficits were calculated from simultaneous records at fast paper speed.

rate, but did not significantly alter cardiac output or mean arterial pressure. The comparison of atrial fibrillation with atrial pacing likewise revealed no significant differences in these variables.

These results differ from those of previous studies (14-19) in which atrial fibrillation consistently reduced cardiac output. Lewis (14) concluded that the hypotension and evidence of reduced cardiac output which he observed during fibrillation were due to the rapid ventricular rates present in his open-chested dogs. Wegria and his associates (15) also studied open-chested dogs, under pentobarbital anesthesia, and did not control ventricular rate. The more recent observations by Skinner, Mitchell, Wallace, and Sarnoff (16) were made in areflexic, open-chested canine preparations with heart block. Although the ventricles were paced at rates comparable to those in the present study, the majority of these experiments were carefully designed to exclude any reflex compensation for the adverse effects of atrial fibrillation. In three dogs with intact reflexes and without heart block, cardiac output and arterial pressure fell at the onset of atrial fibrillation and then tended to return toward control values.

In an extensive study of atrial fibrillation in intact unanesthetized dogs $(17-19,30-32)$, Stewart and his co-workers included a comparison of responses to atrial fibrillation and atrial tachycardia at comparable ventricular rates (30). The ventricular rates were much higher than those in the present study, however, and significant pulse deficits were present (18). Cardiac output was $20 \%$ to $62 \%$ less during atrial fibrillation than during sinus rhythm (17); atrial tachycardia reduced output by an average of only $12 \%$ (30). Administration of digitalis slowed ventricular rates during fibrillation, abolished pulse deficits, 
and resulted in cardiac outputs that were generally higher during fibrillation than during sinus rhythm (31). Roentgenographically determined cardiac silhouettes were larger during atrial fibrillation than during sinus rhythm (32), in spite of a marked increase in ventricular rate which, per se, decreases left ventricular diameter in the intact $\operatorname{dog}(33)$. This observation and the presence of tachycardia during sinus rhythm in all the dogs suggest lingering adverse effects of the ether anesthesia and thoracotomy the animals had undergone the day before the experiments.

It thus appears that variables in addition to the cardiac rhythm influenced the results of these studies. This conclusion is supported by our data indicating marked differences in the effects of atrial fibrillation in the same dogs before and after pentobarbital anesthesia and after thoracotomy. Although the dogs in the present investigation cannot be considered strictly normal, they were obviously more normal than those studied by previous investigators.

There can be no doubt that under appropriate conditions atrial systole contributes significantly to ventricular function (1-8). The absence of any demonstrable reduction in cardiac output during atrial fibrillation, therefore, suggests that compensatory mechanisms quickly offset the loss of atrial systole (and the possible adverse effect of the irregular ventricular response during atrial fibrillation). Such compensatory mechanisms have been postulated previously $(14-16,23)$ to explain the tendency for arterial pressure and cardiac output in open-chested preparations to return toward control values after the onset of atrial fibrillation or tachycardia. In the present study a decrease in the stroke work of the left ventricle at a given end-diastolic diameter was observed upon conversion of atrial fibrillation. Such a shift suggests that positive inotropic influences were acting upon the left ventricle during atrial fibrillation.

Nakano (34) found that reserpine blocks the return of cardiac output toward normal levels during atrial tachycardia in open-chested dogs, and suggested that catecholamines induce this compensation, in response to arterial hypotension. In the present investigation, propranolol was used in an attempt to demonstrate a similar phenomenon. After administration of this drug a small, but sig- nificant, reduction in cardiac output occurred during atrial fibrillation. This does not prove that the observed reduction in output was caused by the associated beta-adrenergic blockade. A nonspecific myocardial depressant effect of propranolol cannot be excluded. If an adrenergic mechanism is responsible for the positive inotropic response to atrial fibrillation, our data do not indicate its exact nature. Arterial hypotension, if present at the onset of fibrillation, was too slight and too transient to be consistently detected.

The reduction in cardiac output induced by atrial fibrillation during exercise may have been due to the associated tachycardia, for atrial systole is more important at rapid heart rates (6). However, beta-adrenergic mechanisms appear to play an important role in the normal cardiovascular response to exercise (35). Possibly, the same mechanisms are utilized in the responses to exercise and to atrial fibrillation. During sufficiently severe exercise, compensation for the adverse effects of atrial fibrillation might become inadequate.

Depletion of myocardial catecholamine stores has been noted in patients with heart failure (36). Whereas the presence of valvular or myocardial lesions may influence the effects of atrial fibrillation in patients with heart disease (10), a reduction in resting cardiac output during atrial fibrillation may reflect a failure of the beta-adrenergic compensatory response to fibrillation in these patients. This hypothesis is supported by a recent report (12) which suggests that atrial fibrillation may have little effect on cardiac output in patients who show no evidence of heart disease.

Atrial fibrillation eliminates effective atrial contractions, increases ventricular rate, and induces a grossly irregular ventricular rhythm. Although the effects of changes in average ventricular rate were controlled in the present study, it is possible that the irregular ventricular response was partially responsible for the adverse effects of atrial fibrillation seen during exercise and beta-adrenergic blockade. Atrial fibrillation may have altered other uncontrolled variables such as coronary blood flow, and thereby adversely influenced ventricular performance. It is therefore not possible to attribute the findings of this investigation to the loss of atrial systole per se. 


\section{Acknowledgments}

We are grateful to Mr. Leon Zornes and Mr. Walter Jones for technical assistance.

\section{References}

1. Gesell, R. A. Auricular systole and its relation to ventricular output. Amer. J. Physiol. 1911, 29, 32.

2. Jochim, K. The contribution of the auricles to ventricular filling in complete heart block. Amer. J. Physiol. 1938, 122, 639.

3. Linden, R. J., and J. H. Mitchell. Relation between left ventricular diastolic pressure and myocardial segment length and observations on the contribution of atrial systole. Circulat. Res. 1960, 8, 1092.

4. Sarnoff, S. J., J. P. Gilmore, and J. H. Mitchell. Influence of atrial contraction and relaxation on closure of mitral valve. Circulat. Res. 1962, 11, 26.

5. Sellers, F. J., D. E. Donald, and E. H. Wood. Atrial contribution to stroke volume in dogs with chronic cardiac denervation (abstract). Physiologist 1962, 5, 211.

6. Mitchell, J. H., D. N. Gupta, and R. M. Payne. Influence of atrial systole on effective ventricular stroke volume. Circulat. Res. 1965, 17, 11.

7. Braunwald, E., and C. J. Frahm. Studies on Starling's law of the heart. IV. Observations on the hemodynamic functions of the left atrium in man. Circulation 1961, 24, 633.

8. Martin, R. H., and L. A. Cobb. Observations on the effect of atrial systole in man. J. Lab. clin. Med. 1966, 68, 224.

9. Burchell, H. B. A clinical appraisal of atrial transport function. Lancet 1964, 1, 775.

10. Braunwald, E. Symposium on cardiac arrhythmias. Introduction, with comments on the hemodynamic significance of atrial systole. Amer. J. Med. 1964, 37, 665 .

11. McIntosh, H. D., Y. Kong, and J. J. Morris, Jr. Hemodynamic effects of supraventricular arrhythmias. Amer. J. Med. 1964, 37, 712.

12. Killip, T., and R. A. Baer. Hemodynamic effects after reversion from atrial fibrillation to sinus rhythm by precordial shock. J. clin. Invest. 1966, 45, 658.

13. Phillips, E., and S. A. Levine. Auricular fibrillation without other evidence of heart disease. A cause of reversible heart failure. Amer. J. Med. 1949, 7, 478.

14. Lewis, T. Fibrillation of the auricles: its effects upon the circulation. J. exp. Med. 1912, 16, 395.

15. Wégria, R., C. W. Frank, G. A. Misrahy, R. S. Sioussat, L. S. Sommer, and G. H. McCormack, Jr. Effect of auricular fibrillation on cardiac output, coronary blood flow and mean arterial blood pressure. Amer. J. Physiol. 1950, 163, 135.
16. Skinner, N. S., Jr., J. H. Mitchell, A. G. Wallace, and S. J. Sarnoff. Hemodynamic consequences of atrial fibrillation at constant ventricular rates. Amer. J. Med. 1964, 36, 342.

17. Stewart, H. J., J. H. Crawford, and A. B. Hastings. The effect of tachycardia on the blood flow in dogs. I. The effect of rapid irregular rhythms as seen in auricular fibrillation. J. clin. Invest. 1926, 3, 435.

18. Stewart, H. J., J. H. Crawford, and A. R. Gilchrist. Studies on the effect of cardiac irregularity on the circulation. I. The relation of pulse deficit to rate of blood flow in dogs subject to artificial auricular fibrillation and to regular tachycardia. $\mathrm{J}$. clin. Invest. 1928, 5, 317.

19. Stewart, H. J., and A. R. Gilchrist. Studies on the effect of cardiac irregularity on the circulation. II. The estimation of cardiac output in dogs subject to artificial auricular fibrillation. J. clin. Invest. $1928,5,335$.

20. Ferguson, T. B., O. W. Shadle, and D. E. Gregg. Effect of blood and saline infusion on ventricular end diastolic pressure, stroke work, stroke volume and cardiac output in the open and closed chest dog. Circulat. Res. 1953, 1, 62.

21. Rushmer, R. F., B. L. Finlayson, and A. A. Nash. Shrinkage of the heart in anesthetized, thoracotomized dogs. Circulat. Res. 1954, 2, 22.

22. Van Citters, R. L., D. L. Franklin, and R. F. Rushmer. Left ventricular dynamics in dogs during anesthesia with alpha-chloralose and sodium pentobarbital. Amer. J. Cardiol. 1964, 13, 349.

23. Nakano, J. Effects of atrial and ventricular tachycardias on the cardiovascular dynamics. Amer. J. Physiol. 1964, 206, 547.

24. Franklin, D. L., D. W. Baker, and R. F. Rushmer. Pulsed ultrasonic transit time flowmeter. I.R.E. Trans. Med. Electron. 1962, BME-9, 44.

25. Rushmer, R. F., D. L. Franklin, and R. M. Ellis. Left ventricular dimensions recorded by sonocardiometry. Circulat. Res. 1956, 4, 684.

26. Baker, D. W., D. L. Franklin, and R. M. Ellis. Miniature electronic instruments for medical research. Research 1960, 13, 275.

27. Franklin, D. L., R. L. Van Citters, and R. F. Rushmer. Left ventricular function described in physical terms. Circulat. Res. 1962, 11, 702.

28. Van Citters, R. L., D. Baker, and R. F. Rushmer. Cardiac adrenergic blockade with DCI in the intact unanesthetized animal. Amer. J. Physiol. 1961, 200, 990.

29. Corday, E., H. Gold, L. B. de Vera, J. H. Williams, and J. Fields. Effect of the cardiac arrhythmias on the coronary circulation. Ann. intern. Med. 1959, 50, 535 .

30. Stewart, H. J., and J. H. Crawford. The effect of tachycardia on the blood flow in dogs. II. The 
effect of rapid regular rhythm. J. clin. Invest. 1926, 3, 449.

31. Stewart, H. J., and A. E. Cohn. Studies on the effect of the action of digitalis on the output of blood from the heart. II. The effect on the output of the hearts of dogs subject to artificial auricular fibrillation. J. clin. Invest. 1932, 11, 897.

32. Stewart, H. J., and J. H. Crawford. The effect of regular and irregular tachycardias on the size of the heart. J. clin. Invest. 1926, 3, 483.

33. Rushmer, R. F. Cardiovascular Dynamics, 2nd ed. Philadelphia, W. B. Saunders, 1961, p. 207.
34. Nakano, J. Effects of atrial and ventricular tachycardia on the cardiovascular dynamics in reserpinized dogs. Amer. J. Cardiol. 1964, 14, 89.

35. Epstein, S., B. F. Robinson, R. L. Kahler, and E. Braunwald. Effects of beta-adrenergic blockade on the cardiac response to maximal and submaximal exercise in man. J. clin. Invest. 1965, 44, 1745.

36. Chidsey, C. A., E. Braunwald, A. G. Morrow, and D. T. Mason. Myocardial norepinephrine concentration in man. Effects of reserpine and of congestive heart failure. New Engl. J. Med. 1963, 269, 653. 